\title{
Extrahepatic Bile Duct Tubular Adenoma
}

National Cancer Institute

\section{Source}

National Cancer Institute. Extrahepatic Bile Duct Tubular Adenoma. NCI Thesaurus. Code C5850.

An adenoma that arises from the extrahepatic bile ducts. It is characterized by the presence of a tubular pattern. 